\title{
Dilatant normal faulting in jointed cohesive rocks: a physical model study
}

\author{
Michael Kettermann ${ }^{1}$, Christoph von Hagke ${ }^{1}$, Heijn W. van Gent ${ }^{1, \mathrm{a}}$, Christoph Grützner ${ }^{2, \mathrm{~b}}$, and Janos L. Urai ${ }^{1}$ \\ ${ }^{1}$ Structural Geology, Tectonics and Geomechanics Energy and Mineral Resources Group, RWTH Aachen University, \\ Lochnerstraße 4-20, 52056 Aachen, Germany \\ ${ }^{2}$ Neotectonics and Natural Hazards, RWTH Aachen University, Lochnerstraße 4-20, 52056 Aachen, Germany \\ anow at: Shell International Exploration and Production Company, The Hague, the Netherlands \\ ${ }^{b}$ now at: COMET; Bullard Laboratories, Department of Earth Sciences, University of Cambridge, Cambridge, UK \\ Correspondence to: Michael Kettermann (michael.kettermann@emr.rwth-aachen.de)
}

Received: 10 December 2015 - Published in Solid Earth Discuss.: 14 January 2016

Revised: 22 April 2016 - Accepted: 16 May 2016 - Published: 27 May 2016

\begin{abstract}
Dilatant faults often form in rocks containing preexisting joints, but the effects of joints on fault segment linkage and fracture connectivity are not well understood. We present an analogue modeling study using cohesive powder with pre-formed joint sets in the upper layer, varying the angle between joints and a rigid basement fault. We analyze interpreted map-view photographs at maximum displacement for damage zone width, number of connected joints, number of secondary fractures, degree of segmentation and area fraction of massively dilatant fractures. Particle imaging velocimetry provides insight into the deformation history of the experiments and illustrates the localization pattern of fault segments. Results show that with increasing angle between joint-set and basement-fault strike the number of secondary fractures and the number of connected joints increase, while the area fraction of massively dilatant fractures shows only a minor increase. Models without pre-existing joints show far lower area fractions of massively dilatant fractures while forming distinctly more secondary fractures.
\end{abstract}

\section{Introduction}

Dilatant faults are ubiquitous features that occur at all scales in the upper crust. Most prominent large-scale examples can be found not only at mid-ocean ridges (Angelier et al., 1997; Friese, 2008; Sonnette et al., 2010; Wright, 1998), intra-plate volcanoes (Holland et al., 2006), continental rifts (Acocella et al., 2003) but also in cemented carbonates and clastics
(Ferrill and Morris, 2003; Moore and Schultz, 1999). They form major pathways for fluid flow, such as water, hydrocarbons or magma, and consequently are of great interest for water and energy supply, geohazard assessment and geodynamics (e.g., Belayneh et al., 2006; Caine et al., 1996; Crone and Haller, 1991; Ehrenberg and Nadeau, 2005; Gudmundsson et al., 2001; Lonergan et al., 2007). Several first-order models for the formation of dilatant fault networks exist (e.g., Abdelmalak et al., 2012; Abe et al., 2011; Acocella et al., 2003; Grant and Kattenhorn, 2004; Hardy, 2013; Holland et al., 2006, 2011; Kettermann and Urai, 2015; van Gent et al., 2010; Vitale and Isaia, 2014; Walter and Troll, 2001). However, the influence of pre-existing cohesionless joints on the formation of faults and fractures is largely untested, although this may have great influence on the fault's geometry and evolution (e.g., Butler, 1989; Giambiagi et al., 2003; McGill and Stromquist, 1979; Schultz-Ela and Walsh, 2002; Virgo et al., 2014). This is also of interest for understanding fluid flow through fault zones for naturally fractured reservoirs (Galland et al., 2006, 2007; Le Corvec et al., 2013).

In this contribution, we focus on the influence of preexisting joints on the formation of dilatant normal fault networks. In particular, we investigate the evolution of dilatant fault networks, which form at different angles with respect to a pre-existing layer-bound joint network. To this end, we performed a series of scaled analogue models. Our first step is to quantify how the angle of pre-existing joints with respect to the active basement fault influences the opening behavior of the fault system. Quantifying this parameter will 
enable us to predict the evolution of segmentation as well as the orientation of secondary faults in the fracture network. In a second step we discuss our results in framework of natural examples: first, the fault network in the Canyonlands $\mathrm{Na}$ tional Park (CLNP), which showcases an open fracture network influenced by pre-existing joints (Fossen et al., 2010; Kettermann et al., 2015; Schultz-Ela and Walsh, 2002); second, volcanic environments, in particular mid-ocean ridges as for example exposed in the rift zone in Iceland (Angelier et al., 1997), and caldera collapse in Campi Flegrei, Italy (Vitale and Isaia, 2014).
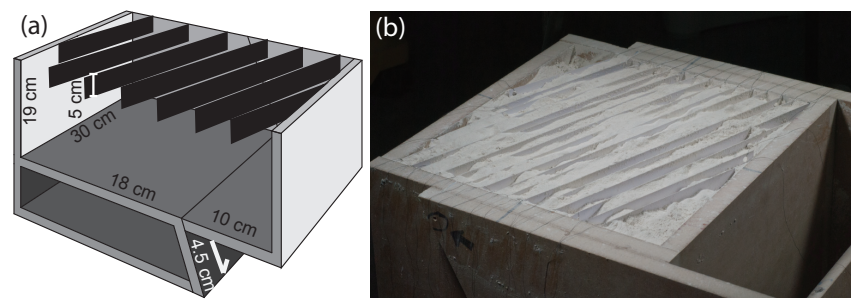

Figure 1. (a) Dimension and principle setup of the deformation apparatus. Black bands symbolize paper sheets that are used for joint creation. (b) Experiment after sieving in the hemihydrate powder, with the paper sheets still in place. Paper sheets are removed before deformation begins.

\section{Analogue modeling of dilatant faults in a jointed host rock}

For our experiments we used the analogue device designed by Holland et al. (2011), which has a length, width and depth of $28 \times 30 \times 19 \mathrm{~cm}$, respectively (Fig. 1). This box has a dipslip half-graben geometry, with a basement-fault dip of $60^{\circ}$, and maximum displacement is $4.5 \mathrm{~cm}$. Throughout this article we quantify displacement as percentage of sediment layer thickness. Therefore, the maximum displacement of $4.5 \mathrm{~cm}$ at a layer thickness of $19 \mathrm{~cm}$ translates to $23.7 \%$ displacement. Modeling material as well as our experimental setup is based on previous analogue models of dilatant fault networks (Holland et al., 2006, 2011; van Gent et al., 2010). We used hemihydrate $\left(\mathrm{CaSO}_{4} \times 0.5 \mathrm{H}_{2} \mathrm{O}\right)$ powder because it has a well-known cohesion and tensile strength and can develop vertical walls. Therefore, it is suitable to implement cohesionless joints into the models and produce dilatant faults and open fractures. The properties of the material are well known (van Gent et al., 2010). The powder compacts easily, and increasing sieving height leads to higher densities in the sandbox. This trend stops at a sieving height of about $30 \mathrm{~cm}$, at which the powder reaches a constant velocity due to a balance of air friction and gravity (Holland et al., 2011; van Gent et al., 2010). After sieving from a height $>30 \mathrm{~cm}$, the powder has a density of $732 \mathrm{~kg} \mathrm{~m}^{3}$ and a porosity of $75 \%$. Tensilestrength is $9 \mathrm{~Pa}$ (method after Schweiger and Zimmermann,

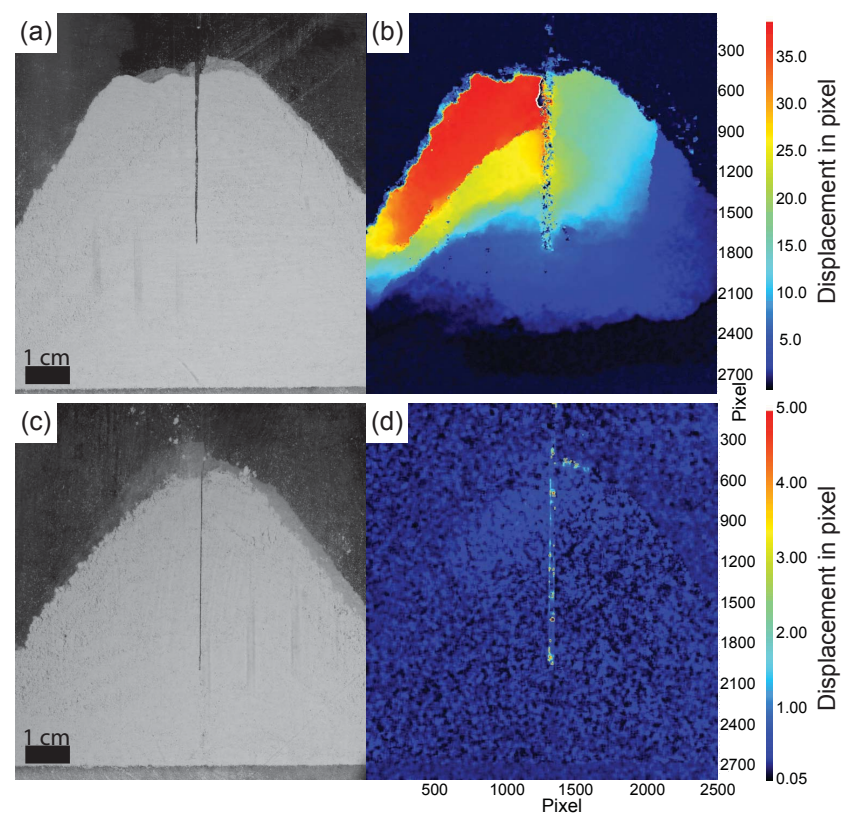

Figure 2. (a, b) Raw photo and deformation analysis of a joint in a hemihydrate powder pile created by impressing a blade. The powder is strongly affected. (c, d) Raw photo and deformation analysis of a joint in a hemihydrate powder pile created by sieving the powder around a sheet of paper and removing it afterwards (note the different scale bar for displacement). The removing-paper method proves to be the better choice.

1999) for the uncompacted powder, increasing proportionally to the pre-compaction stress. The cohesion derived from shear tests is about $40 \mathrm{~Pa}$. Both tensile strength and cohesion increase with increasing compaction, i.e., overburden pressure or burial depth in the box.

We scaled our experiments as discussed by van Gent et al. (2010) and applying the laws derived by Schellart (2000). For example, a model height of $19 \mathrm{~cm}$ represents approximately $600 \mathrm{~m}$ of sandstone in nature with a cohesion of $70 \mathrm{MPa}$. Our model geometry was scaled approximately to the joint and graben system of CLNP, where $\sim 100 \mathrm{~m}$ deep vertical joints cut through present day 400-500 m brittle sediments pre-faulting (McGill and Stromquist, 1979); i.e., $5 \mathrm{~cm}$ joints in a $19 \mathrm{~cm}$ powder column). The material properties limit the testing of increasing joint depths. The hemihydrate powder collapses under its own weight in shear in a depth of about $7 \mathrm{~cm}$ (van Gent et al., 2010). It is hence not possible to test the influence of joints cutting the entire $19 \mathrm{~cm}$ hemihydrate column. However, smaller joint depths may influence fault evolution. A thorough analysis of this effect would require extensive experimental series, testing different joint depths at different angles. This is beyond the scope of this study, and we leave analysis of different materials as well as different joint depths for future work. 


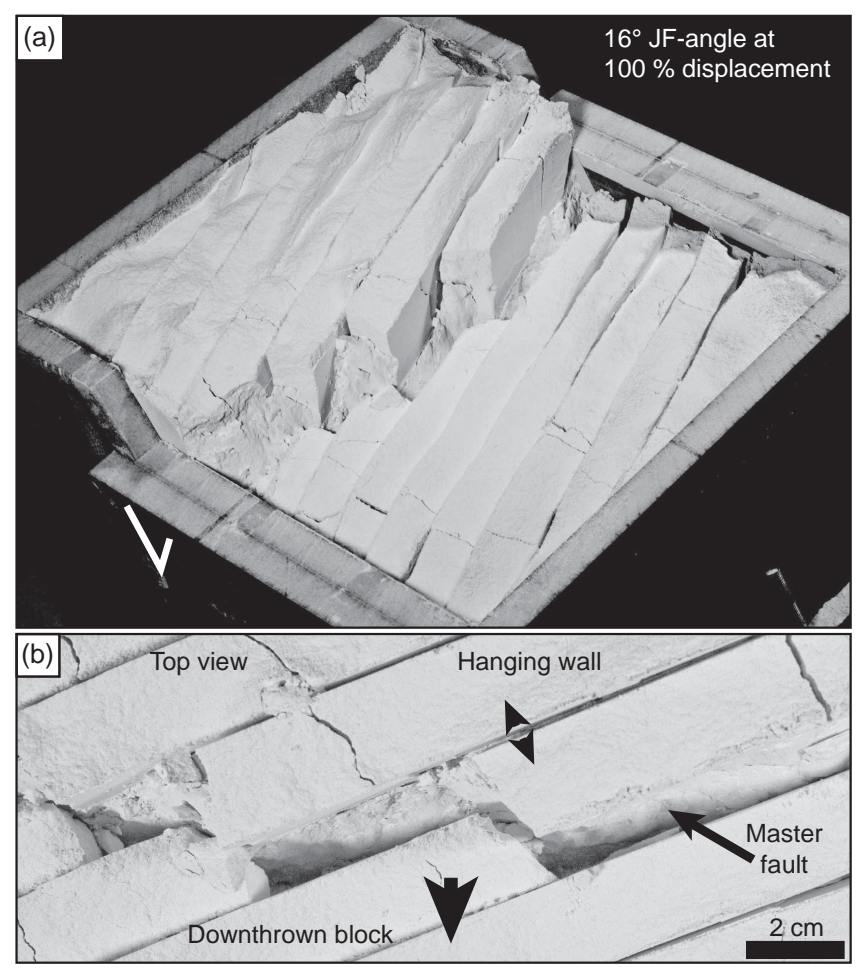

Figure 3. (a) Oblique view of the $16^{\circ} \mathrm{JF}$-angle showing deformation localized at pre-existing joints and step-over structures. (b) Top-view photograph of the same experiment shows the typical zigzag shape formed by step-overs at the master fault.

As the powder is very sensitive to compaction, it is important to form joints without damage to the surrounding material. An initial test using a blade led to compaction of particles adjacent to produced joints (Fig. 2a, b). Minimum disturbances were achieved by mounting thin, low-friction paper sheets in the box with spacing of $2.5 \mathrm{~cm}$ prior to sieving. Removing the paper after filling the box leaves cohesionless, open $(<1 \mathrm{~mm}$ aperture) joints without compacting or fracturing the surrounding material (Fig. 2c, d) and furthermore guarantees consistent depths of the joints. In order to reduce friction between the powder and the side walls, paper sheets are mounted along the moving side walls and removed before starting the experiments. However, in some cases extraction of these paper sheets caused fractures orthogonal to joint strike at the outer edges of the experiment (i.e., close to the wall), visible before starting the experiment. These fractures may open during initial stages of the experiment, but they do not accommodate much strain and do not influence fault geometry (see below). As these fractures are artifacts and can be followed throughout the experiments, we did not include them in the quantitative analyzes. The joints penetrate $5 \mathrm{~cm}$ deep into the powder (Fig. 1). We performed experiments with systematically increasing angles between the joints and the basement fault $\left(0,4,8,12,16,20\right.$ and $\left.25^{\circ}\right)$. The jointfault angle is in the following referred to as JF-angle.
In analogue models where no erosion is applied, deformation within the sandbox is reflected at the surface. A useful tool to measure the surface evolution of analogue models is particle image velocimetry (PIV) (e.g., Adam et al., 2005; Holland et al., 2006). To enhance contrast, we added some sand grains to the hemihydrate powder at the top of the experiments. The small amount of sand $(\ll 1 \mathrm{vol} . \%$ o) is assumed to have no influence on the mechanics of the powder column or fault development. We recorded our experiments with two computer-controlled DSLR cameras (Nikon D80 and D90 with resolutions of 10 and 12 million pixels, respectively), one in top view and one in oblique view (Fig. 3). We use the top-view photographs for PIV analysis (shot with the Nikon D90) to identify areas of the model at which deformation localizes and calculate the displacement fields. All images are corrected for lens distortion using verified lens distortion profiles that are included in the Adobe CameraRaw software. Details on the used lenses and focal lengths are given in Table 1 . With this analysis, we detect which joints are reactivated at which state of deformation. The oblique view provides an optic impression of strain distribution on different joints and the 3-D geometry of the model.

\section{Analogue modeling results}

We started our series with an experiment without pre-existing joints as a reference (Fig. 4a). In this experiment, the master fault shows a concave shape towards the hanging wall over the width of the box. This is a reasonably expected result as the fault that develops in our cohesive material is subvertical close to the surface and thus substantially steeper than the predefined $60^{\circ}$ fault dip of the sandbox. Close to the sidewalls of the box friction forces the powder to follow the $60^{\circ}$ dip of the basement fault further towards the footwall. Where uninfluenced by sidewall effects, the fault forms as dilatant fault with vertical fault scarp close to the model's surface. The fault surface is rugged and a small volume of rubble fills the opening gap at the fault (Holland et al., 2006; van Gent et al., 2010). A dense and interconnected network of secondary fractures parallel to the master fault forms gradually during fault evolution as a result of fault migration. The fault shape shows no clear pattern but is rather undulating in map view. An antithetic fault forms as well and shows the same type of migration and fracture network as the master fault. Overall we note that the observed fault and fracture pattern in homogeneous material is very different as compared to inhomogeneous experiments with pre-existing joints, as expected (cf. Fig. 4a, b). In the following we describe observations of the structural evolution of experiments with pre-existing joints including quantitative analyses of key parameters. Figure 5 shows top-view images and the corresponding PIV results (summed up vector fields) for all experiments, which we will describe in the following. In order to identify and distinguish parts of the model that 
Table 1. Summary of lens types and focal lengths used for top-view photography.

\begin{tabular}{lrrrrrrr}
\hline JF-angle & $0^{\circ}$ & $4^{\circ}$ & $8^{\circ}$ & $12^{\circ}$ & $16^{\circ}$ & $20^{\circ}$ & $25^{\circ}$ \\
\hline Lens & $18-135 \mathrm{~mm}$ & $18-135 \mathrm{~mm}$ & $18-135 \mathrm{~mm}$ & $12-24 \mathrm{~mm}$ & $12-24 \mathrm{~mm}$ & $12-24 \mathrm{~mm}$ & $12-24 \mathrm{~mm}$ \\
& $\mathrm{f} / 3.5-5.6$ & $\mathrm{f} / 3.5-5.6$ & $\mathrm{f} / 3.5-5.6$ & $\mathrm{f} / 4.0$ & $\mathrm{f} / 4.0$ & $\mathrm{f} / 4.0$ & $\mathrm{f} / 4.0$ \\
Focal & $28 \mathrm{~mm}$ & $35 \mathrm{~mm}$ & $28 \mathrm{~mm}$ & $24 \mathrm{~mm}$ & $24 \mathrm{~mm}$ & $24 \mathrm{~mm}$ & $24 \mathrm{~mm}$ \\
Length & & & & & & & \\
\hline
\end{tabular}

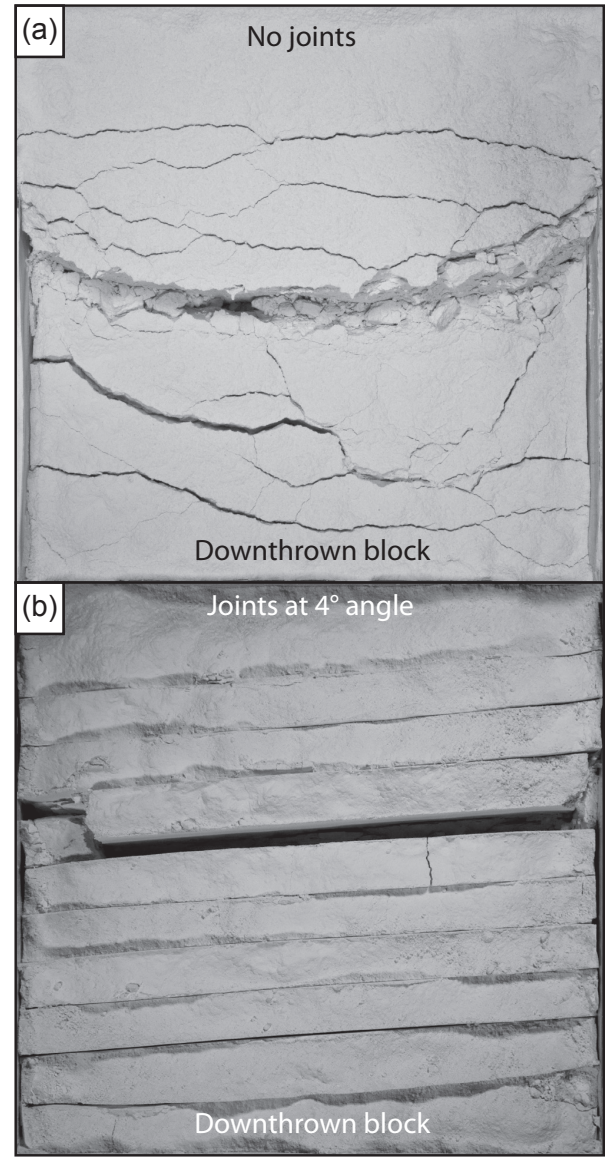

Figure 4. (a) Top-view photo of an experiment without pre-existing joints. Note the rather rugged shape of the mater fault and the minor fractures. (b) Top-view photograph of the experiment with a $4^{\circ} \mathrm{JF}$ angle. All deformation localizes at the pre-existing joints.

experience different amounts of deformation we show the total displacement vectors summing up the entire deformation until maximum displacement. Movies produced from image series of all experiments and from respective PIV images (divergence of the displacement field) are freely accessible at https://doi.pangaea.de/10.1594/PANGAEA.859151.

Our observations can be subdivided into two categories. First, features which can be observed in all experiments, and develop after a similar amount of strain applied. Secondly, as opposed to these consistent features, we observe features that are variable, i.e., change with increasing an- gle between basement-fault strike and joint orientation. A consistent feature is the formation of secondary joints oriented at high angle to the pre-existing joints, initiating during the first $2.4 \%$ displacement (\% of layer thickness) and increasing in number during the experiment (best visible in Fig. 5g). Another consistent feature is the formation of conjugate faults (indicated by dashed yellow lines in all experiments shown in Fig. 5). However, they show a wider range of initiation time, starting at $3.8 \%$ displacement $\left(12^{\circ}\right.$ degree $\mathrm{JF}$-angle) up to $11.8 \%$ displacement ( $16^{\circ} \mathrm{JF}$-angle) We note that onset of the formation of conjugates is not related to the JF-angle but varies randomly (cf. also movies at doi:10.1594/PANGAEA.859151). A third consistent observation is that fault localization starts in the footwall and propagates stepwise towards the hanging wall, always localizing at and reactivating pre-existing joints (cf. model in Fig. 6).

All experiments share a curvature of the fault scarp towards the footwall at the boundaries, which is a boundary effect caused by the design of the deformation box, similar to what has been observed in the experiment without preexisting joints (cf. Fig. 4a, b). Friction on the sidewalls of the box between the pre-defined $60^{\circ}$ fault and the fault localizing at the $90^{\circ}$ dipping vertical joints causes material to break off (red arrows in Fig. 5). This effect is limited to the outermost few centimeters of the model and is therefore interpreted as an artifact caused by the boundary condition and is not included in the interpretation.

A variable feature of increasing importance with JF-angle is the localization of faults at pre-existing joints, i.e., reactivation of joints. In the experiment with $0^{\circ} \mathrm{JF}$-angle the fault never cuts through the material between joints but only jumps from joints in the footwall towards joints in the hanging wall (Fig. 5a). With increasing JF-angle the master faults as well as the conjugates form step-overs between individual joints with fracture orientations at a high angle to the pre-existing joints (e.g., Fig. 5d). The fault reactivates pre-existing joints and needs to accommodate the distinct deviation between the basement-fault strike and joint strike. At higher JF-angles, the fault connects increasingly more pre-existing joints via step-overs (Fig. 7a). The main structural and geometrical features observed at the master fault such as step-overs and distribution of strain over different fault strands and reactivated joints occur in the same way in the conjugates, although with less displacement and therefore less prominent (cf. dashed red and yellow lines in all photographs in Fig. 5). 


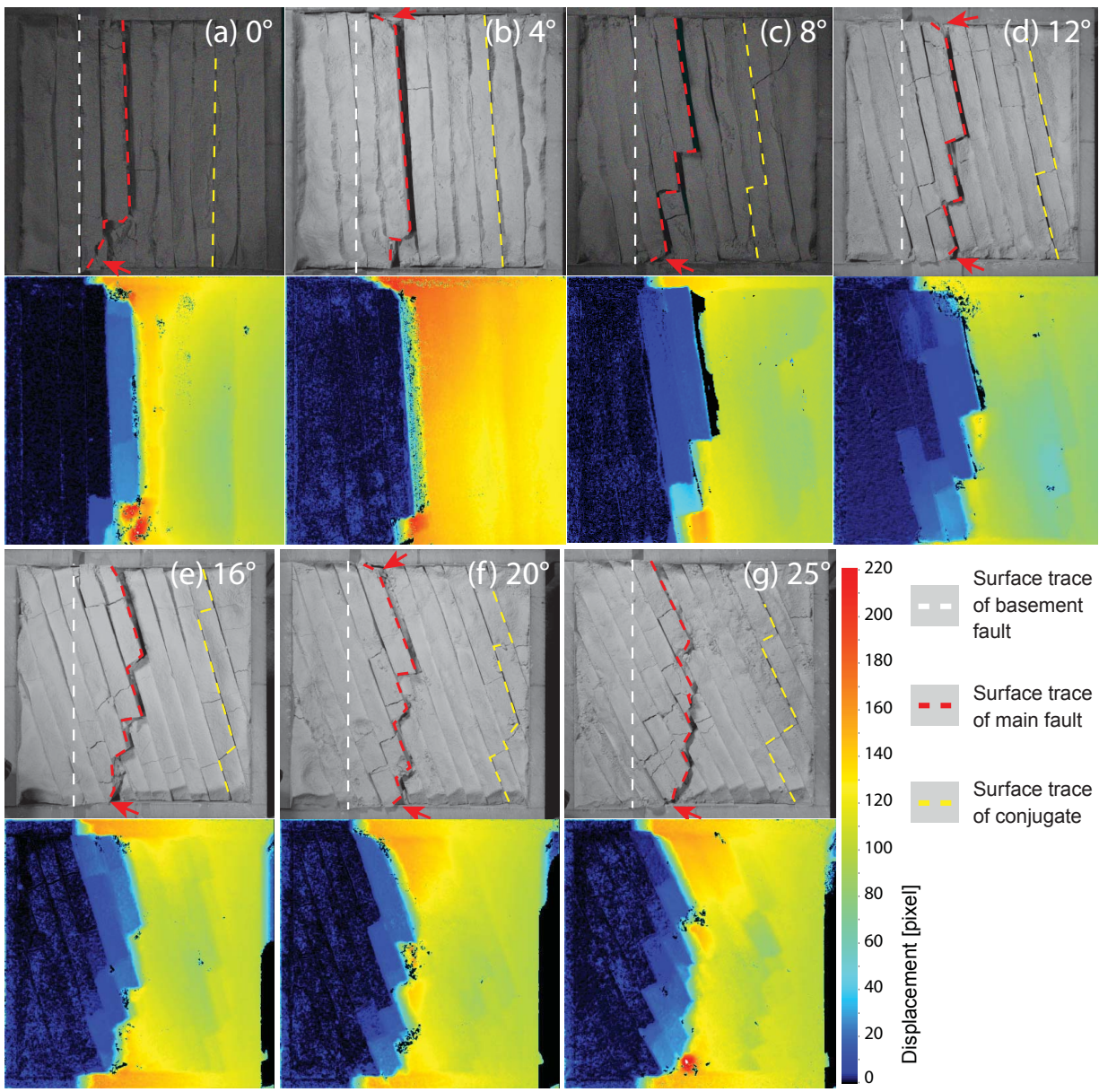

Figure 5. Map-view photographs of the experiment series at maximum displacement. Red lines mark the master fault; yellow lines mark the main antithetic fault. White lines illustrate the extent of the basement fault at the surface. For each experiment we show a respective PIV image illustrating the total deformation in map view. Color code gives the displacement in pixels. Note that different blocks experienced different amounts of displacement, while localization is always at pre-existing joints.
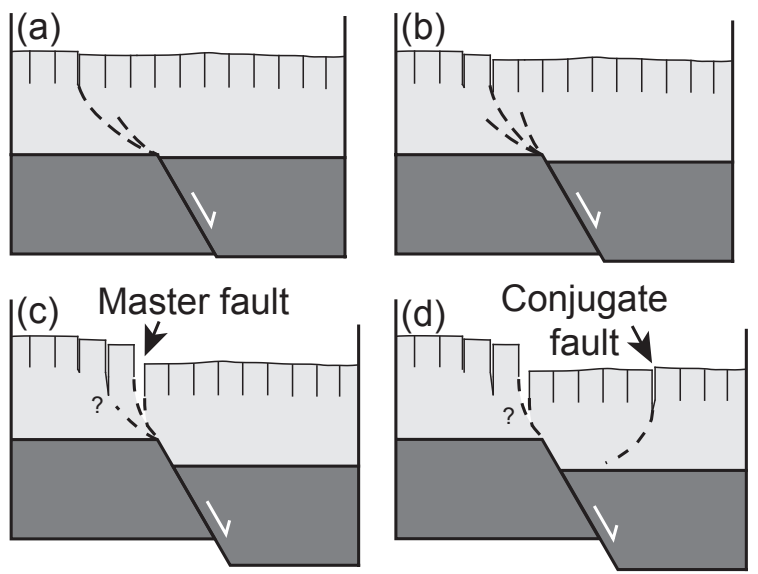

Figure 6. Conceptual sketch illustrating the development of a typical joint controlled fault zone in side view.
At step-overs the fault does not localize at the base of the joints but forms a wedge shaped structure (Fig. 8). This is because the fault cannot change its position abruptly but forms a hard link (Peacock and Sanderson, 1991). Additionally, where the fault cuts through unfractured material, rubble forms and falls into the opening voids.

An additional feature that occurs in experiments with high JF-angle is reverse faulting within the graben, striking roughly orthogonal to the basement-fault strike. As the reverse faults form from bottom to top and do not necessarily propagate to surface, the related surface expression is difficult to see in photographs. Figure 9 provides a compilation of a top-view photograph $\left(25^{\circ} \mathrm{JF}\right.$-angle at $95 \%$ displacement; Fig. 9a), a PIV analysis displaying the y-component of the displacement field, which is roughly parallel to the formed reverse faults (Fig. 9b), and a PIV image showing the divergence of the displacement field, which clearly shows locations of compression that indicate reverse faulting (Fig. 9c). To clearly see the formation of the reverse 


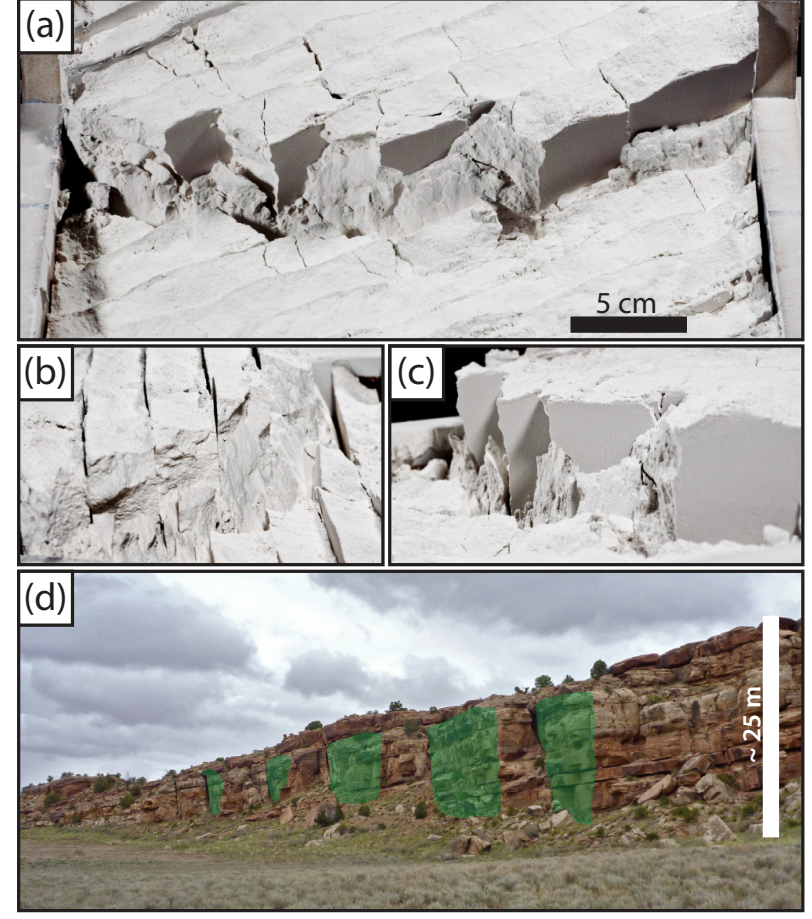

Figure 7. (a) Front view of the experiment with $25^{\circ} \mathrm{JF}$-angle. (b) View from left side. (c) View from right side. (d) Comparable structures in Canyonlands National Park. Green areas mark joint surfaces.

faults, the reader is referred to the corresponding top-view movie (https://doi.pangaea.de/10.1594/PANGAEA.859151). At the pre-cut bounding walls the $60^{\circ}$ basement-fault angle is enforced on the powder column by friction, hindering the formation of deep grabens. In the center of the box, however, the fault develops freely with a steep master fault, which causes the formation of deeper grabens. The resulting subsidence gradient, with shallow grabens at the sides and deeper grabens in the center of the experiments, creates a space problem which results in the formation of reverse faults. However, we observed reverse faults with minor displacements in only two experiments $\left(20\right.$ and $\left.25^{\circ}\right)$ and they are accompanied by extensional fractures, which allow us to assume no important effect of the reverse faults on the studied features.

\section{Quantitative analysis of the analogue models}

In order to quantify the effect of JF-angle, we carried out analyses of the following measurable parameters using interpreted map-view images (see Fig. 10 for interpreted map and illustration of measured parameters): Maximum damage zone width, area fraction of open gaps, degree of segmentation, number of secondary fractures and number of connected pre-existing joints within the damage zone. For quantifying damage zone width, we measure the maximum distance be-

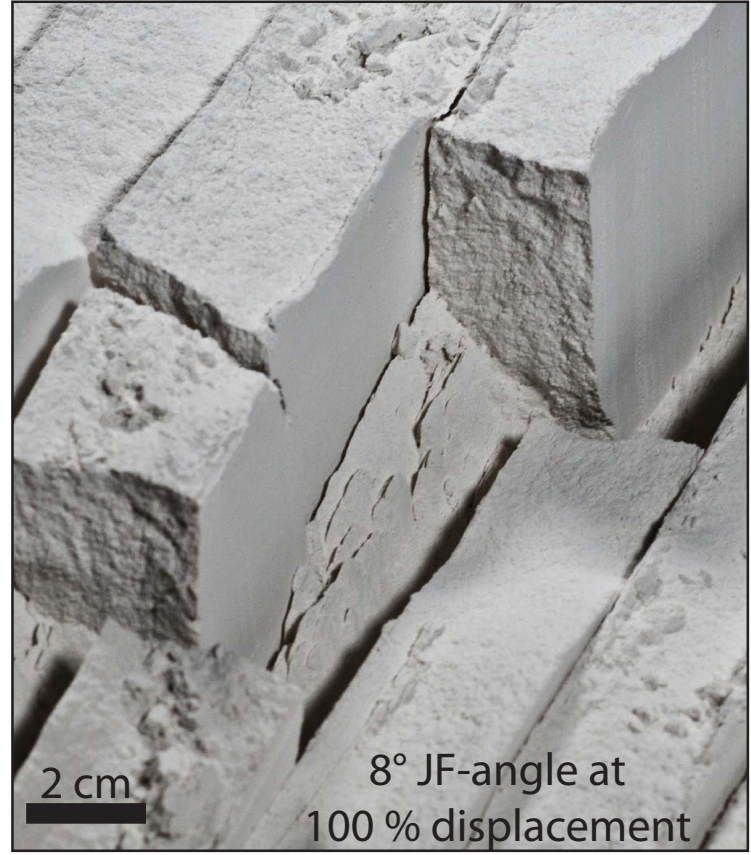

Figure 8. Wedge shape at a fault step-over.

tween the unfractured parts of the host rock around the master fault (see Fig. 10). In cases where damage by the master fault cannot be separated from damage by the antithetic fault, half the distance between both is assumed as damage zone boundary. To measure the area fraction of open gaps, we manually traced the open fracture networks and quantified their percentage of bulk area using the ImageJ software (Abràmoff et al., 2004). Degree of segmentation is the total number of pre-existing joints accommodating strain, which was determined using PIV analysis. Eventually, we measure the angles between pre-existing joints and secondary fractures using ArcMap software (ESRI - Environmental Systems Resource Institute, 2014). Top-view photographs of all experiments and their interpretation can be found in the Appendix. Table 2 summarizes the measured data.

Our quantitative analyses show an increase of all analyzed attributes from small to large JF-angles for angles larger than $8^{\circ}$ (Fig. 11). Initial positions of the joints with respect to the basement fault may be important for small JF-angles. In our experimental setup, joint spacing is close enough that the master fault underlies several joints. Hence the influence of joints on fault evolution at $0^{\circ}$ may be interpreted quantitatively. However, the position of joints with respect to the master fault for the $4^{\circ} \mathrm{JF}$-angle experiment may be inconclusive due to insufficient cross-cuttings between the joints and the master fault. The possible number of JF intersects can be 0 or 1 in our deformation box depending on the initial joint position. A substantially wider box would result in one or more intersections and consequently lead to the formation of step-overs. This cannot be represented in our data due to 
Table 2. Summary of the measured data. Plot in Fig. 11.

\begin{tabular}{lrrrrr}
\hline JF-angle & $\begin{array}{r}\text { Number of } \\
\text { secondary } \\
\text { fractures }\end{array}$ & $\begin{array}{r}\text { Interconnectivity } \\
\text { (number of } \\
\text { connected joints) }\end{array}$ & $\begin{array}{r}\text { Area } \\
\text { fraction of } \\
\text { open gaps }\end{array}$ & $\begin{array}{r}\text { Damage zone } \\
\text { width }(\mathrm{cm})\end{array}$ & $\begin{array}{r}\text { Degree of } \\
\text { segmentation }\end{array}$ \\
\hline No joints & $>40$ & - & 5.2 & 13.5 & - \\
$0^{\circ}$ & 9 & 4 & 8.2 & 9.3 & 4 \\
$4^{\circ}$ & 5 & 4 & 8.34 & 9.5 & 7 \\
$8^{\circ}$ & 7 & 4 & 8.8 & 9.9 & 5 \\
$12^{\circ}$ & 17 & 9 & 8.3 & 12.6 & 7 \\
$16^{\circ}$ & 23 & 9 & 9.5 & 12.9 & 9 \\
$20^{\circ}$ & 19 & 10 & 11.5 & 10.8 & 8 \\
$25^{\circ}$ & 28 & 11 & 11.1 & 10.25 & 13 \\
\hline
\end{tabular}

limited box width. However, at JF-angles of $8^{\circ}$ and higher, at least two intersections between master fault and joint occur, independent of the initial location of the joints with respect to basement fault. This implies that we can always observe joint-fault interaction at least at two independent points, and results may be interpreted quantitatively.

In addition to these general trends we note that the area fraction of open fractures increases by only $3 \%$ and varies throughout the experimental series. The increasing trend is most pronounced in the number of secondary fractures, the number of connected joints and the degree of segmentation, which increases by over $150 \%$, about $100 \%$ and about $130 \%$, respectively. Interestingly, the secondary fractures are more abundant in the footwall. However, in the experiment without pre-existing joints we count more than 40 secondary fractures and a damage zone width of $13.5 \mathrm{~cm}$, both exceeding all measured values of experiment with pre-existing joints, while the area fraction of open gaps with $5.2 \%$ is smaller (data points are marked with filled square, circle and star in Fig. 11).

Rose diagrams plotting pre-existing joints and secondary fractures show that the orientation of secondary fractures is always at a high angle to joint strike (Fig. 12). Overall, we observe that the main fault gap is increasingly filled with rubble with increasing JF-angle.

\section{Discussion - faulting in jointed rocks}

\subsection{Deformation at different angles}

Our experiments provide insights on how pre-existing joints influence normal faults in nature. In our experiments, the most counterintuitive result is the observation that most of the secondary fractures initially occur in the footwall of the normal fault rather than in the hanging wall, where most strain is accommodated at a later stage. This implies that deformation initiates in the footwall, probably at relatively long distance with respect to the normal fault (few centimeters). During ongoing deformation, the secondary fractures gradu- ally step over into the hanging wall, until a steady state with mostly hanging wall deformation is reached. Figure 13 shows six PIV images of the experiment with $12^{\circ} \mathrm{JF}$-angle illustrating the progressive evolution of a fault at 2, 9, 13, 23, 42 and $14.7 \%$ displacement. Therefore, if a fault system is still evolving, major fluid pathways are located in the footwall, whereas in long-lived steady state fault systems substantial additional fluid pathways are created in the hanging wall of the master fault.

The second important observation is that the connectivity of the joints increases with increasing JF-angle. This rather straightforward result has likewise large implications on fluid flow through the system, as connectivity and fracture surface increase. Whereas at low JF-angles fluid flow is concentrated in a small area with low connectivity, systems with higher JFangles provide a wide zone of interconnected fractures. Our study for the first time is able to quantitatively show this connectivity increase and related parameters (Fig. 11). In areas of variable angle between joints and faults, which probably is rather the rule than the exception, this should be considered. Examples for such settings may be the CLNP or carbonate fields of the Middle East (Daniel, 1954).

We note that the damage zone width decreases for JFangles larger than $16^{\circ}$. We interpret this to be the result of reduced influence of the joints on the fault trace. At high JFangles it is easier for the fault to fracture the intact material than to deviate far from its preferred orientation while following the pre-existing joints. However, although the damage zone is narrower, the number of joints that are connected via the master fault is increasing.

\subsection{Comparison to other models}

Whereas studies on interaction between dilatant joints and faults are limited, the interaction of multiple stages of shear faulting has been studied in analogue models by several authors. Henza et al. $(2010,2011)$ performed experiments in which two phases of faulting at different angles were applied. The major difference to our models is the different material: Henza et al. (2010) use wet clay that does not lose 


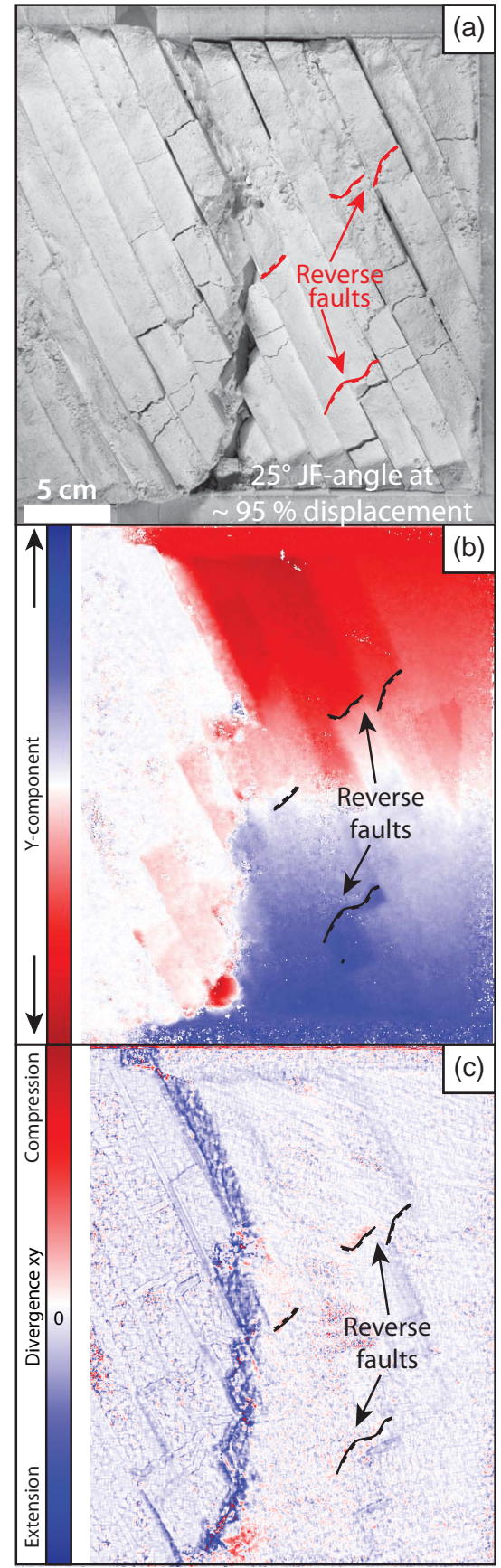

Figure 9. (a) Reverse faults marked in top-view photograph of experiment with $25^{\circ} \mathrm{JF}$-angle at $95 \%$ displacement. (b) PIV image displaying the $y$ component of the displacement field. Sharp changes in color intensity indicate compression or dilation. (c) PIV image showing the summed up divergence of the displacement field. Red colors show areas of local compression, i.e., reverse faulting.

cohesion at fractures or faults, whereas we use dry powder forming cohesionless joints and open fractures. The different approaches are valid for different natural examples. In these experiments, second-phase faulting localizes at first-

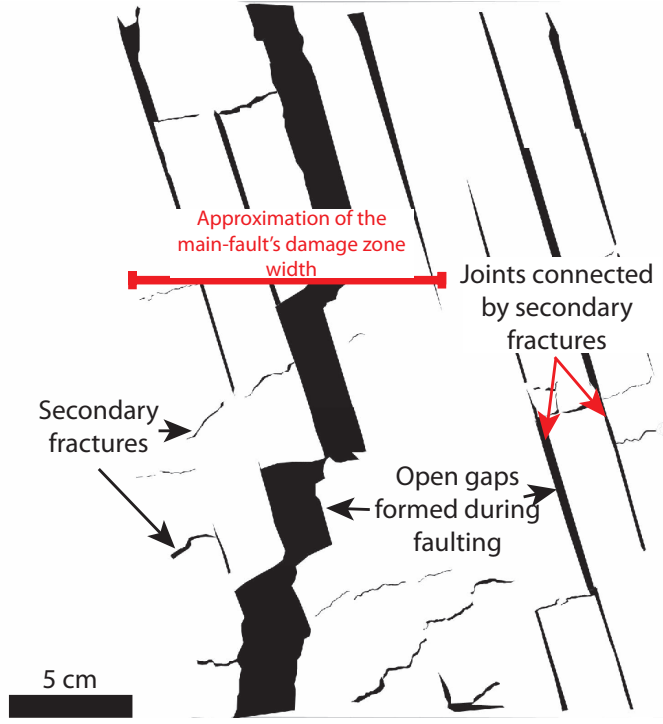

Figure 10. Top-view image of interpreted newly opened fractures at maximum displacement, exemplary of the $16^{\circ} \mathrm{JF}$-angle experiment. Image shows the interpretation routine for estimating damage zone width, secondary fractures, joints connected by secondary fractures and open gaps formed during faulting. Photos and interpretations for all experiments are shown in the Appendix.

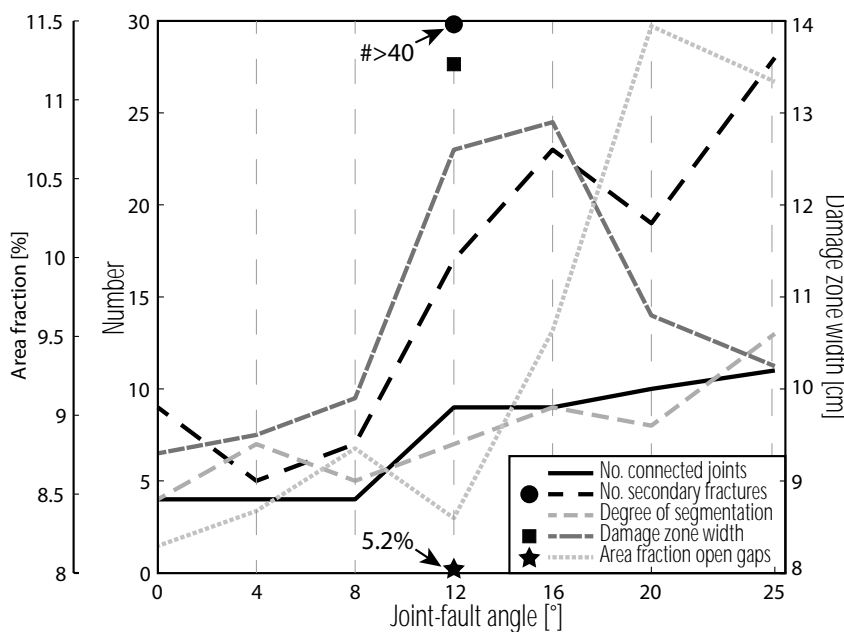

Figure 11. Results of the quantitative analysis. For definitions of the individual parameters please refer to Sect. 3.1.

phase faults but also forms new faults. Similarly, map views of the experiments of Henza et al. (2010) and of this study are comparable. The number of newly formed fault segments increases with increasing angle between maximum principal stresses of first- and second-phase faulting. Our experiments corroborate these findings, as we observe a systematic increase of the number of new formed fractures and fault segments at step-overs. The result is a zigzagged map-view fault geometry comparable to this study. However, in the clay experiments by Henza et al. (2010), step-overs do not de- 

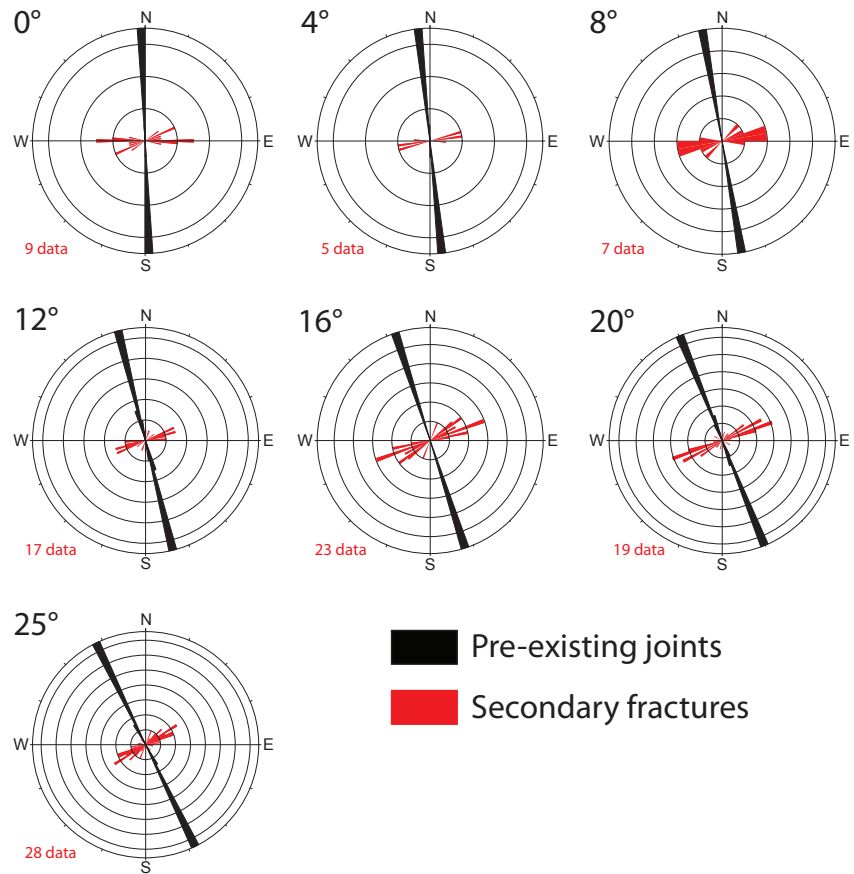

Figure 12. Rose plots showing the orientation of pre-existing joints (black) and secondary fractures (red) for all experiments. Strike direction of the basement fault is N-S. Note that secondary fractures are always at a high angle to the pre-exiting joints.

velop at the high angles we observe. Kattenhorn et al. (2000) showed that the angle of secondary joints is related to the ratio between fault-parallel and fault-perpendicular stress. This stress ratio differs for cohesive faults as in the experiments of Henza et al. (2010) and cohesionless joints as in the presented models, explaining the different orientations of secondary fractures.

\subsection{Comparison to natural examples}

Our results have direct implications for our understanding of natural dilatant fault systems in jointed rocks. The inherent complexity of naturally fractured rocks, however, makes it difficult to transfer all observations made in the lab to one particular outcrop. The best natural example that we also chose as base for the scaling of our experiments is the grabens area of the Canyonlands National Park, Utah, USA, which is an archetype for dilatant faults in jointed rocks (e.g., McGill and Stromquist, 1979; Moore and Schultz, 1999; Rotevatn et al., 2009). The northern part of the grabens is characterized by prominent vertical joint sets, which are older than the formation of the dilatant faults (McGill and Stromquist, 1979; Schultz-Ela and Walsh, 2002). The most prominent joint set consists of up to several $100 \mathrm{~s}$ of meters long joints cutting through the upper $100 \mathrm{~m}$ of sandstone and roughly follows a NNE-SSW striking arcuate geometry of the graben-bounding faults. The grabens of CLNP developed

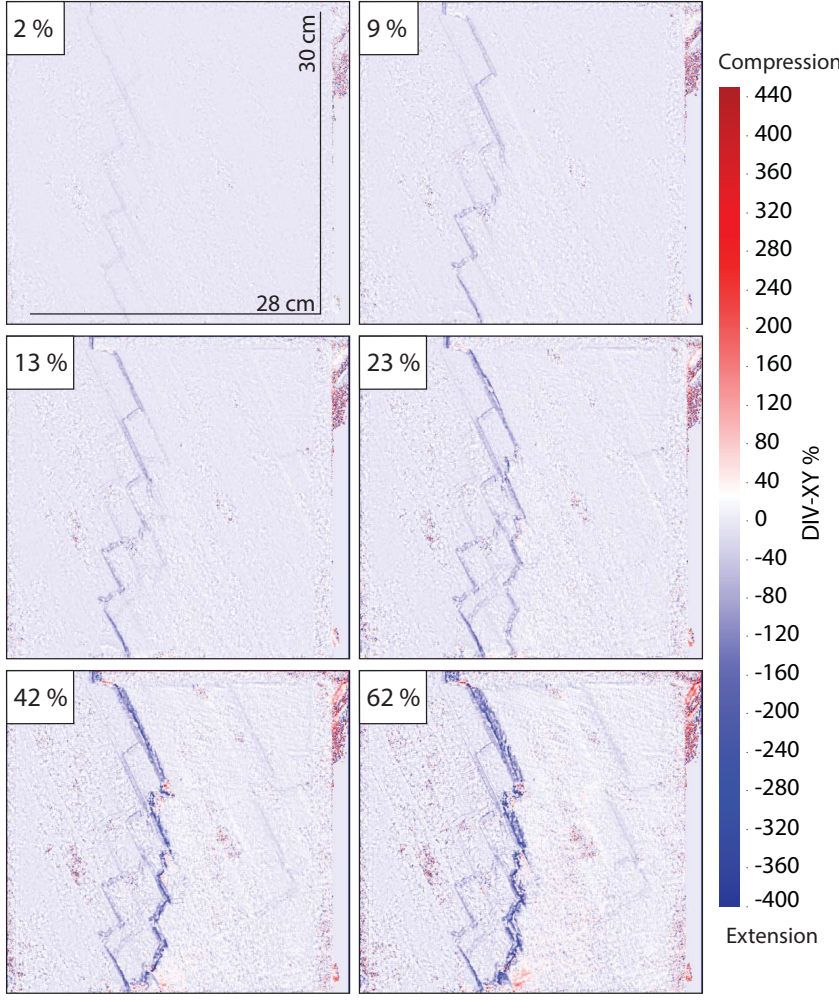

Figure 13. PIV images series of the $12^{\circ} \mathrm{JF}$-angle experiment showing the summed up divergence of the displacement field (extension: blue; compression: red). Note how different joints are reactivated at different stages of deformation.

as an extensional fault array on top of a deforming layer of evaporites. Faults dip at $60-80^{\circ}$ below the jointed layer (Kettermann et al., 2015; McGill and Stromquist, 1979; Moore and Schultz, 1999), comparable to our model setup. Angles between this joint-set and fault strikes inferred from local trends range between $0^{\circ}$ and $\sim 25^{\circ}$ (Kettermann et al., 2015), which is the range covered in our experiments.

The following structural elements observed in the experiments are also present and common in the field. Where joints are at an angle with respect to the orientation of the grabens, i.e., not normal to the regional direction of extension, faults step over from one joint to another forming the typical zigzagged shape (cf. Fig. 7d). Airborne imagery (Utah Automated Geographic Reference Center, 2009) of three selected areas shows different JF-angles and the resulting step-over geometries (Fig. 14). As in the experiments, the distance between step-overs increases from small JF-angles (Fig. 14b) to larger angles (Fig. 14d).

The graben walls are surfaces of pre-existing joints at which the faults localize (Kettermann et al., 2015). Comparable to the models, in the field we infer a progressive migration of the graben-bounding faults towards the footwall by reactivating several pre-existing joints before a steady master fault forms. This is expressed by minor displacements 

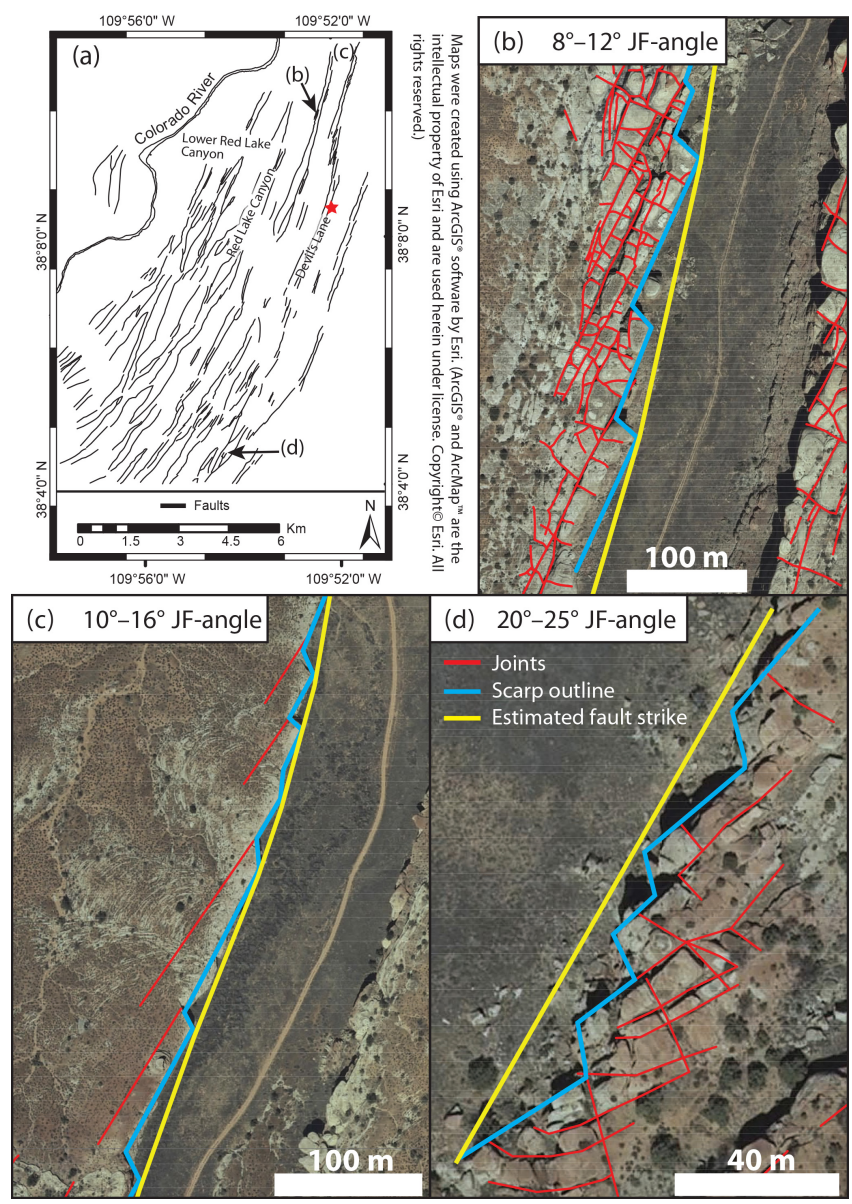

Figure 14. Collection of airborne photographs with interpretations of joints (red), estimated fault strike (yellow) and scarp outline (blue) of selected areas in Canyonlands National Park. (a) Fault map of the grabens of Canyonlands National Park. Locations of (b), (c) and (d) are shown as well as Fig. 15d. North is up in all images. (b) 8-12 $\mathrm{JF}$-angle. (c) $10-16^{\circ} \mathrm{JF}$-angle. (d) $20-25^{\circ} \mathrm{JF}$-angle.

reactivating some joints in the footwall, before eventually a stable master fault forms and accumulates most offset. Figure 15 shows elevation profiles of the $0^{\circ} \mathrm{JF}$-angle experiment (Fig. 15a, derived from photogrammetry) and a location with $0^{\circ} \mathrm{JF}$-angle in Devil's Lane (Fig. 15b, location marked in Fig. 14a by red star; National Elevation Dataset (NED) courtesy of the US Geological Survey). Both show the same stair steps formed by faults reactivating pre-existing joints with increasing displacement from east to west before the main graben-bounding fault formed.

As graben walls are vertical and faults dip shallower at depth, open fissures form at reactivated joints. In the field these are mostly filled with rubble and Quaternary sediments but at numerous locations sinkholes resulting from dilatational faulting exist where sediment and rainwater are transported into the subsurface (Biggar and Adams, 1987; Kettermann et al., 2015). Ground-penetrating radar studies (Kettermann et al., 2015) suggest that the hanging walls of the
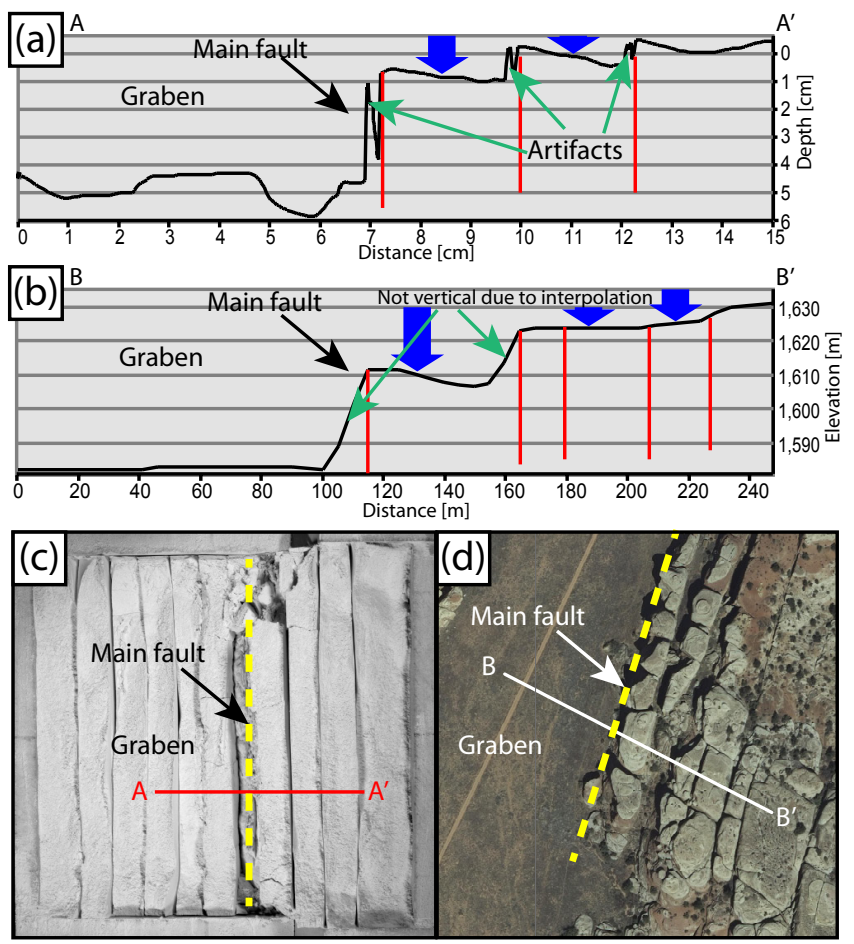

Figure 15. Comparison of elevation profiles from experiment (a) and nature (b). Both show typical stair step geometry caused by incremental reactivation of joints by fault migration from footwall to hanging wall. Location of the profiles shown in (c) and (d) for experiment and nature, respectively. Location of (d) marked in Fig. 14a by red star. Sharp spikes in elevation in a are artifacts of photogrammetric 3-D reconstruction caused by shadows in open gaps. Inclined slopes in (b) instead of vertical surfaces result from interpolation of the elevation model. In reality these are vertical joint surfaces (cf. Kettermann et al., 2015).

graben-bounding faults (i.e., the graben floors) are faulted as well, which is in agreement with the observations of our models. This shows that our models are capable of correctly reproducing the characteristic features observed in similar natural settings, allowing us in turn to make predictions of natural fault systems from these models. For example, our models suggest that along the graben-bounding faults in the subsurface, interconnected fluid pathways exist that are partially filled with uncemented coarse grain sediments and rubble.

However, there are limits to the comparability of our experiments and the graben fault system. In CLNP a second set of pre-existing joints exists which is oriented roughly orthogonal to the NNE-SSW striking joint set. This joint set is parallel to orientation of the developing secondary fractures observed in our analogue experiments. As a result we are not able to compare formation and extent of secondary fractures observed in the models with structures in CLNP. Likewise, the exact position of step-over geometries may be affected, as they localize at and reactivate early formed sec- 
ondary fractures. The existence of step-overs is, however, unquestionable, as they are elemental features in areas where faults interact with jointed rocks (Myers and Aydin, 2004).

Another example of normal faulting in pre-fractured cohesive rocks is the caldera collapse in Campi Flegrei, southern Italy. During collapse, faults reactivate steep pre-existing joints, and detailed analysis of the fracture pattern and younger faults shows that the collapse is controlled by the inherited structures (Vitale and Isaia, 2014). This interaction localizes later volcanic activity in areas adjacent to the caldera. Our modeling efforts corroborate these findings and show that it is formation of step-overs and distribution of strain across several normal faults which cause new craters to form preferentially in areas of high JF-angles.

The rift zone in Iceland shows similar features. Faults often localize along vertical cooling joints, resulting in a planar fault geometry with abrupt changes of fault dip controlled by the depth extent of joints rather than a pure listric shape (Angelier et al., 1997). This characteristic fault shape could be observed in the grabens of CLNP or in faulted basalts on Hawaii (Holland et al., 2006) and in the presented experiments and is more or less independent of the angle between joints and faults. Holland et al. $(2006,2011)$ propose a connectivity of open fractures along faults up to great depths based on field and laboratory observations. Our models suggest that this connectivity can be enhanced by the existence of pre-existing vertical joints as they tend to open and connect via secondary fractures during faulting.

However, the presented results are valid only for pure dipslip normal faulting. Oblique faulting can produce similar structures without pre-existing joints as shown by Grant and Kattenhorn (2004) in the rift zone on Iceland. Here, vertical joints in an angle with respect to the general fault strike trend are formed in the very early stages of deformation. The resulting structures are mostly comparable to the ones described in this paper, but the temporal and genetic relationship between faults and joints is different and joints are relatively short in extend as they are related to the local faulting rather than a regional process.

\section{Conclusions}

We studied the influence of pre-existing vertical, cohesionless joints on the development of faults with different angles between both. Robust structural features that occur in the models as well as in field prototypes and similar experiments validate our models. In detail we could show that

- the damage zone width increases by about $50 \%$ and the secondary fractures within this zone by more than $100 \%$ with increasing $\mathrm{JF}$-angle from 0 to $25^{\circ}$;

- the map-view area fraction of open gaps increases only by $3 \%$ over the tested range;
- antithetic faults show similar geometries and damage zone dimensions as the master fault;

- secondary joints and step-overs are oriented orthogonal to the primary joint orientation;

- experiments without pre-existing joints show a wider fracture network with a higher fracture density, while at the same time providing less open space. However, due to the length of the pre-existing open joints, areas far beyond the fractured parts are connected to the system.

In summary, the angle between pre-existing joints and faults has a distinct effect on the network of open fractures mostly in terms of fracture surfaces and connectivity, while the volume of open space does not change dramatically. However, fluid pathways are created over a large area which has a strong influence on fluid flow. Structures in our models compare well with field prototypes such as the grabens of CLNP, suggesting a predictive capability of these models. Investigating the influence of parameters such as joint spacing or dimensions will be part of future work in combination with discrete element models that allow the investigation of detailed fracture connectivity at depth.

\section{Data availability}

For each experiment three movies compiled from image series are provided showing (1) top-view, (2) oblique view and (3) divergence of the displacement field derived from PIV analyses. Movies are published as data set: https://doi.pangaea.de/10.1594/PANGAEA.859151 (doi:10.1594/PANGAEA.859151) Filenames are in the format <JF-ANGLE>-<TYPE>. <MOV> (e.g., "4degtopview.mov"). 


\section{Appendix A}

The following two figure panels show a top-view photograph at maximum displacement for each experiment and the corresponding interpreted map that was used for analyses.
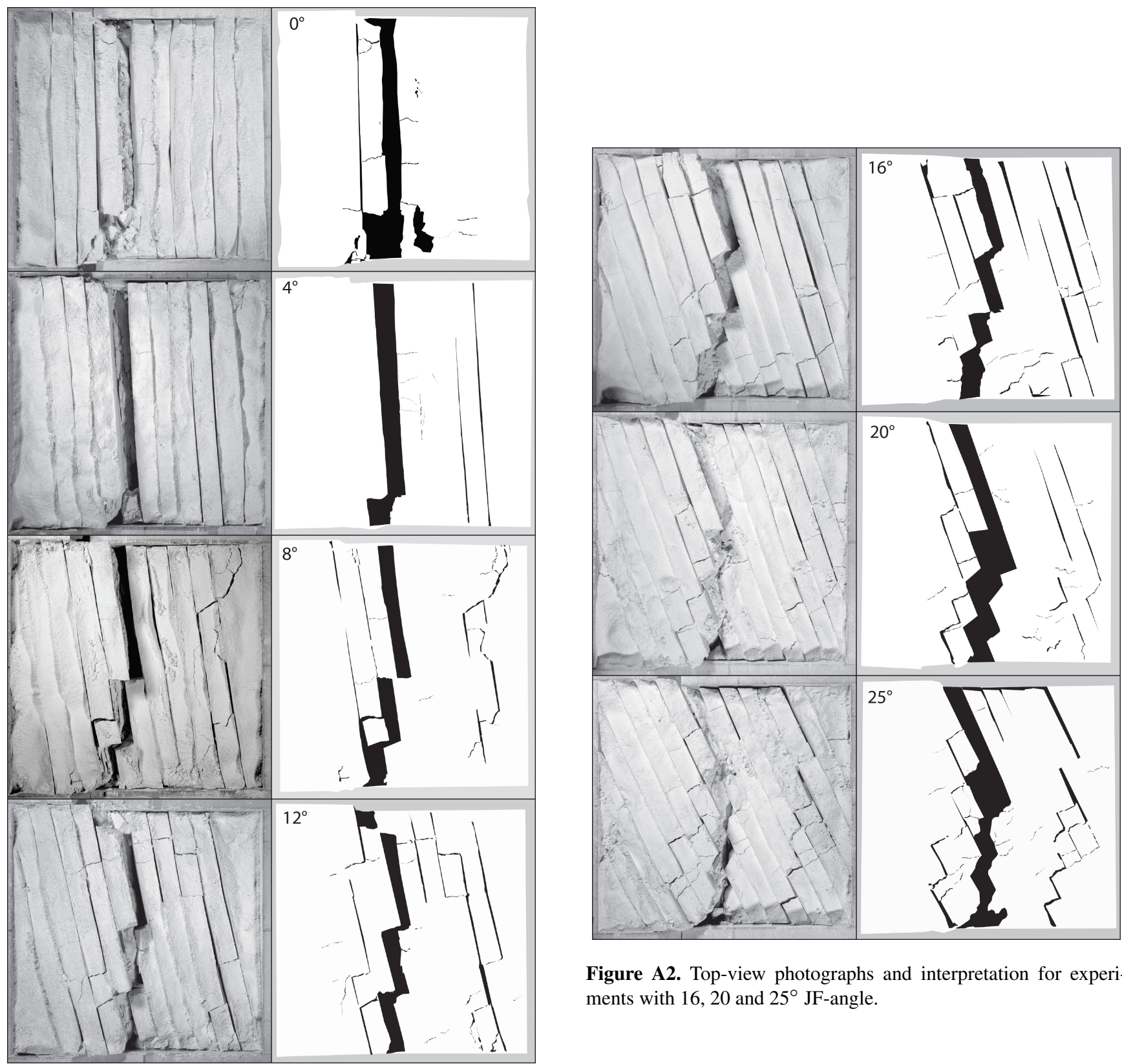

Figure A2. Top-view photographs and interpretation for experiments with 16,20 and $25^{\circ} \mathrm{JF}$-angle.

Figure A1. Top-view photographs and interpretation for experiments with $0,4,8$ and $12^{\circ} \mathrm{JF}$-angle. 
Acknowledgements. We like to thank Joceline Koch for helping with the data analysis and Marc Miller and Vicky Webster from the US National Park Service for their kind support in the preparation of the field study in Canyonlands National Park. We also greatly appreciate thorough and constructive reviews of Andrea Billi and Olivier Galland that helped to improve the quality this article.

Edited by: F. Rossetti

\section{References}

Abdelmalak, M. M., Mourgues, R., Galland, O., and Bureau, D.: Fracture mode analysis and related surface deformation during dyke intrusion: Results from 2D experimental modelling, Earth Plane. Sc. Lett., 359/360, 93-105, 2012.

Abe, S., van Gent, H. W., and Urai, J. L.: DEM Simulation of Normal Faults in cohesive Materials, Tectonophysics, 512, 12-21, 2011.

Abràmoff, M. D., Magalhães, P. J., and Ram, S. J.: Image processing with image, J. Biophotonics Int., 11, 36-41, 2004.

Acocella, V., Korme, T., and Salvini, F.: Formation of normal faults along the axial zone of the Ethiopian Rift, J. Struct. Geol., 25, 503-513, 2003.

Adam, J., Urai, J.L., Wieneke, B., Oncken, O., Pfeiffer, K., Kukowski, N., Lohrmann, J., Hoth, S., van der Zee, W., and Schmatz, J.: Shear localisation and strain distribution during tectonic faulting - new insights from granular-flow experiments and high-resolution optical image correlation techniques, J. Struct. Geol., 27, 283-301, 2005.

Angelier, J., Bergerat, F., Dauteuil, O., and Villemin, T.: Effective tension-shear relationships in extensional fissure swarms, axial rift zone of northeastern Iceland, J. Struct. Geol., 19, 673-685, 1997.

Belayneh, M., Geiger, S., and Matthai, S. K.: Numerical simulation of water injection into layered fractured carbonate reservoir analogs, AAPG Bull., 90, 1473-1493, 2006.

Biggar, N. E. and Adams, J. A.: Dates derived from Quaternary strata in the vicinity of Canyonlands National Park, in: Geology of Cataract Canyon and Vicinity: A Field Symposium - Guidebook of the Four Corners Geological Society, edited by: Campbell, J. A., Canyonlands Research Bibliography, Paper No. 327, 127-136, 1987.

Butler, R. W. H.: The influence of pre-existing basin structure on thrust system evolution in the Western Alps, Geol. Soc. Lond. Spec. Publ., 44, 105-122, 1989.

Caine, J. S., Evans, J. P., and Forster, C. B.: Fault zone architecture and permeability structure, Geology, 24, 1025-1028, 1996.

Crone, A. J. and Haller, K. M.: Segmentation and the coseismic behavior of basin and range normal faults, Examples from eastcentral Idaho and southwestern Montana, USA, J. Struct. Geol., 13, 165-176, 1991.

Daniel, E. J.: Fractured Reservoirs of Middle-East, AAPG Bull., 38, $774-815,1954$.

Ehrenberg, S. N. and Nadeau, P. H.: Sandstone vs. carbonate petroleum reservoirs: A global perspective on porosity-depth and porosity-permeability relationships, AAPG Bull., 89, 435-445, 2005.
ESRI - Environmental Systems Resource Institute: ArcMap 11.2, ESRI, Redlands, California, 2014.

Ferrill, D. A. and Morris, A. P.: Dilational normal faults, J. Struct. Geol., 25, 183-196, 2003.

Fossen, H., Schultz, R. A., Rundhovde, E., Rotevatn, A., and Buckley, S. J.: Fault linkage and graben stepovers in the Canyonlands (Utah) and the North Sea Viking Graben, with implications for hydrocarbon migration and accumulation, AAPG Bull., 94, 597613, 2010.

Friese, N.: Brittle tectonics of the Thingvellir and Hengill volcanic systems, Southwest Iceland: field studies and numerical modelling, Geodin. Acta, 21, 169-185, 2008.

Galland, O., Cobbold, P. R., de Bremond d'Ars, J., and Hallot, E.: Rise and emplacement of magma during horizontal shortening of the brittle crust: Insights from experimental modeling, J. Geophys. Res., 112, B06402, doi:10.1029/2006JB004604, 2007.

Galland, O., Cobbold, P. R., Hallot, E., de Bremond d'Ars, J., and Delavaud, G.: Use of vegetable oil and silica powder for scale modelling of magmatic intrusion in a deforming brittle crust, Earth Planet. Sc. Lett., 243, 786-804, 2006.

Giambiagi, L. B., Alvarez, P. P., Godoy, E., and Ramos, V. A.: The control of pre-existing extensional structures on the evolution of the southern sector of the Aconcagua fold and thrust belt, southern Andes, Tectonophysics, 369, 1-19, 2003.

Grant, J. V. and Kattenhorn, S. A.: Evolution of vertical faults at an extensional plate boundary, southwest Iceland, J. Struct. Geol., 26, 537-557, 2004.

Gudmundsson, A., Berg, S. S., Lyslo, K. B., and Skurtveit, E.: Fracture networks and fluid transport in active fault zones, J. Struct. Geol., 23, 343-353, 2001.

Hardy, S.: Propagation of blind normal faults to the surface in basaltic sequences: Insights from 2D discrete element modelling, Mar. Petrol. Geol., 48, 149-159, 2013.

Henza, A. A., Withjack, M. O., and Schlische, R. W.: Normal-fault development during two phases of non-coaxial extension: An experimental study, J. Struct. Geol., 32, 1656-1667, 2010.

Henza, A. A., Withjack, M. O., and Schlische, R. W.: How do the properties of a pre-existing normal-fault population influence fault development during a subsequent phase of extension?, J. Struct. Geol., 33, 1312-1324, 2011.

Holland, M., Urai, J. L., and Martel, S.: The internal structure of fault zones in basaltic sequences, Earth Planet. Sc. Lett., 248, 301-315, 2006.

Holland, M., van Gent, H. W., Bazalgette, L., Yassir, N., Hoogerduijn-Strating, E. H., and Urai, J. L.: Evolution of dilatant fracture networks in normal faults - evidence from 4D model experiments, Earth Planet. Sc. Lett., 304, 399-406, 2011.

Kattenhorn, S. A., Aydin, A., and Pollard, D. D.: Joints at high angles to normal fault strike: an explanation using 3-D numerical models of fault-perturbed stress fields, J. Struct. Geol., 22, 1-23, 2000.

Kettermann, M. and Urai, J. L.: Changes in structural style of normal faults due to failure mode transition: First results from excavated scale models, J. Struct. Geol., 74, 105-116, 2015.

Kettermann, M., Grützner, C., van Gent, H. W., Urai, J. L., Reicherter, K., and Mertens, J.: Evolution of a highly dilatant fault zone in the grabens of Canyonlands National Park, Utah, USA integrating fieldwork, ground-penetrating radar and airborne im- 
agery analysis, Solid Earth, 6, 839-855, doi:10.5194/se-6-8392015, 2015.

Kettermann, M., von Hagke, C., van Gent, H. W., Grützner, C., and Urai, J. L.: Physical models of dilatant normal faulting in jointed cohesive rocks, doi:doi:10.1594/PANGAEA.859151, 2016.

Le Corvec, N., Menand, T., and Lindsay, J.: Interaction of ascending magma with pre-existing crustal fractures in monogenetic basaltic volcanism: an experimental approach, J. Geophys. Res.Sol. Ea., 118, 968-984, 2013.

Lonergan, L., Jolly, R. H. J., Rawnsley, K., and Sanderson, D. J.: Fractured reservoirs, Geol. Soc. London, 270, 285 pp., 2007.

McGill, G. E. and Stromquist, A. W.: The grabens of Canyonlands National Park, Utah, Geometry, mechanics, and kinematics, J. Geophys. Res., 84, 4547-4563, 1979.

Moore, J. M. and Schultz, R. A.: Processes of faulting in jointed rocks of Canyonlands National Park, Utah, Geol. Soc. Am. Bull., 111, 808-822, 1999.

Myers, R. and Aydin, A.: The evolution of faults formed by shearing across joint zones in sandstone, J. Struct. Geol., 26, 947-966, 2004.

Peacock, D. C. P. and Sanderson, D. J.: Displacements, segment linkage and relay ramps in normal fault zones, J. Struct. Geol., 13, 721-733, 1991.

Rotevatn, A., Buckley, S. J., Howell, J. A., and Fossen, H.: Overlapping faults and their effect on fluid flow in different reservoir types: A LIDAR-based outcrop modeling and flow simulation study, AAPG Bull., 93, 407-427, 2009.

Schellart, W.: Shear test results for cohesion and friction coefficients for different granular materials: scaling implications for their usage in analogue modelling, Tectonophysics, 324, 1-16, 2000.

Schultz-Ela, D. D. and Walsh, P.: Modeling of grabens extending above evaporites in Canyonlands National Park, Utah, J. Struct. Geol., 24, 247-275, 2002.
Schweiger, A. and Zimmermann, I.: A new approach for the measurement of the tensile strength of powders, Powder Technol., 101, 7-15, 1999.

Sonnette, L., Angelier, J., Villemin, T., and Bergerat, F.: Faulting and fissuring in active oceanic rift: Surface expression, distribution and tectonic-volcanic interaction in the Thingvellir Fissure Swarm, Iceland, J. Struct. Geol., 32, 407-422, 2010.

Utah Automated Geographic Reference Center: US Geological Survey, National Elevation Dataset (NED), 10 m resolution, HRO 1 Foot Color Orthophotography, 2009.

van Gent, H. W., Holland, M., Urai, J. L., and Loosveld, R.: Evolution of fault zones in carbonates with mechanical stratigraphy - Insights from scale models using layered cohesive powder, J. Struct. Geol., 32, 1375-1391, 2010.

Virgo, S., Abe, S., and Urai, J. L.: The evolution of crack-seal vein and fracture networks in an evolving stress field: insights from Discrete Element Models of fracture sealing, J. Geophys. Res., 119, 8708-8727, 2014.

Vitale, S. and Isaia, R.: Fractures and faults in volcanic rocks (Campi Flegrei, southern Italy): Insight into volcano-tectonic processes, Int. J. Earth Sci., 103, 801-819, 2014.

Walter, T. R. and Troll, V. R.: Formation of caldera periphery faults: an experimental study, Bull. Volcanol., 63, 191-203, 2001.

Wright, D. J.: Formation and Development of Fissures at the East Pacific Rise: Implications for Faulting and Magmatism at Mid-Ocean Ridges, in: Faulting and Magmatism at Mid-Ocean Ridges, edited by: Roger, W., Buck, P. T. D., Karson, J. A., and Lagabrielle, Y., American Geophysical Union, Washington, DC, 137-151, 1998. 